\title{
An investigation of the spread of gentamicin resistance in a district general hospital
}

\author{
GABRIELLE M. FISHER, M. C. KELSEY* and E. MARY COOKE \\ Division of Hospital Infection, Central Public Health Laboratory, Colindale, London NW9 $5 H T$ and \\ *Department of Pathology, Barnet General Hospital, Wellhouse Lane, Barnet, Herts EN5 3DJ
}

\begin{abstract}
Summary. A cluster of infections caused by gentamicin-resistant gram-negative bacilli in a District General Hospital was investigated. The plasmids coding for gentamicin resistance in the infecting organisms and in isolates obtained from the ward environment and from the faeces of patients and staff were characterised. Six plasmids encoding gentamicin resistance were recognised amongst the organisms causing infection. Two of the plasmids were found in different serotypes of the same species and one plasmid was found in different genera. Three of the plasmids present in the organisms causing the infections were also present in the inanimate environment or in the bowel flora of patients and these also were found in different serotypes of the same species and in different genera.
\end{abstract}

\section{Introduction}

Most of the gram-negative bacilli responsible for infection are part of the normal intestinal flora; others are free-living organisms that have established themselves in moist places in the hospital environment, though it is generally accepted that the hospital environment does not have an important role as a source of gram-negative organisms causing infections in patients (Wenzel et al., 1977; Maki et al., 1982). Many are multi-resistant organisms and are selected by use of various antibiotics. The aminoglycosides remain antibiotics of first choice in the seriously ill infected hospital patient and the occurrence of gentamicin-resistant Enterobacteriaceae is still regarded with concern in the United Kingdom. Their isolation may lead to the introduction of infection-control measures to prevent further dissemination of the strain, although the source of the original isolate is seldom known. Recent understanding of the mechanisms of antimicrobial resistance and the knowledge that resistance can spread between species has led to an increased interest in the spread of resistance amongst microbial populations by spread of plasmids encoding multiple resistances (Rennie and Duncan, 1977; O'Brien et al., 1980; Tompkins et al., 1980; Rubens et al., 1981). Although the source of these plasmids is rarely identifiable, one potential reservoir has been identified as Klebsiella strains

Received 8 Mar. 1985; accepted 17 Sep. 1985.

* Present address: Department of Microbiology, Whittington Hospital, Highgate, London N19 5NF.
(Casewell et al., 1981; Milch and Ke, 1981). Plasmid transfer is known to occur in the human gastrointestinal tract (Anderson et al., 1973; Petrocheilou et al., 1976) but little is known about the acquisition of plasmids in the environment.

We recently investigated a cluster of infections in a district general hospital caused by gentamicinresistant klebsiellae and infections caused by various gentamicin-resistant gram-negative bacilli which had occurred in the same hospital in the preceding months. We identified several different gentamicin-resistance plasmids distributed amongst the isolates. We therefore decided to examine the ward environment not only for the species in which we had detected those plasmids, but also for similarly multi-resistant organisms and to study their plasmids. The possibility of intra-species plasmid transfer as well as cross infection was considered, and an investigation of the plasmid content of the clinical strains together with those of gentamicin-resistant strains from the inanimate environment and faeces of staff and patients of an affected ward was performed, in the hope of finding environmental reservoirs of the incriminated strains or their plasmids.

\section{Materials and methods}

\section{Bacteria}

One hundred and four isolates of gentamicin-resistant gram-negative bacilli were used in this study; 37 (table I) were isolated during a period of 6 months (Jun.-Dec., 1982) from infections occurring in 34 patients in eight wards of a district general hospital. The hospital has 450 
acute beds and is one of primary referral. The remainder of the organisms (table III) were isolated in Dec. 1982 from the environment of one of the wards (A) in which 16 members of staff, 16 patients and 75 inanimate sites were sampled.

Strains used as recipients in resistance-transfer experiments were Escherichia coli $\mathrm{K} 12$ 14R525 $\mathrm{F}^{-} \mathrm{lac}^{+} \mathrm{Nx}^{\mathrm{R}}$ (Frost et al., 1982) and E. coli $\mathrm{K} 12 \mathrm{~J} 62.2 \mathrm{lac}^{-}$prohis trp ${ }^{-} \mathrm{Rf}^{\mathrm{R}}$ and Pseudomonas aeruginosa PU21 $\mathrm{Rf}^{\mathrm{R}}$ (Datta et al., 1980).

\section{Media and antimicrobial agents}

Commercial culture media used were Nutrient Broth (Oxoid no. 2) (NB), nutrient agar (NB+1.3\% w/v New Zealand agar) (NA), Tryptone Soy Broth (Oxoid) (TSB), and Diagnostic Sensitivity Test Agar (Oxoid) (DST) to which lysed horse blood $5_{\%}^{\circ} \mathrm{V} / \mathrm{v}$ was routinely added. Antibiotics were obtained from commercial sources: amikacin, carbenicillin, chloramphenicol (Sigma); ampicillin (Beecham); gentamicin. cefotaxime (Roussel); cephradine (Von Heyden); kanamycin, nalidixic acid (Winthrop); rifampicin (Ciba); streptomycin (Glaxo); trimethoprim, sulphamethoxazole (Burroughs Wellcome); tetracycline (Cyanamid) and tobramycin (Eli Lilly).

\section{Maintenance and growth of bacteria}

Acinetobacter sp. and Pseudomonas sp. other than $P$. aeruginosa were grown at $30^{\circ} \mathrm{C}$, all others at $37 \mathrm{C}$, in NB and maintained at room temperature on NA slopes.

\section{Isolation of bacteria from the ward environment}

Swabs from inanimate objects and faecal samples $(1 \mathrm{~g})$ from staff and patients in ward A were cultured in TSB containing sodium deoxycholate (BDH) $0.05 \% \mathrm{w} / \mathrm{v}$ and gentamicin $4 \mu \mathrm{g} / \mathrm{ml}$, at $37 \mathrm{C}$. overnight. to select for growth of gentamicin-resistant and moderately-resistant gram-negative bacteria. Colonies were isolated on the same medium solidified with New Zealand agar $1.3 \% \mathrm{w} / \mathrm{v}$. Clones were selected on the basis of morphology and purified, then characterised by standard methods. Klebsiella, $P$. aeruginosa and multi-resistant $E$. coli isolates were further characterised by serological typing. Isolates were distinguished by species. type, source and antimicrobial sensitivity.

\section{Antibiotic-sensitivity testing}

Cultures were screened by a break-point method for resistance to a wide range of antibiotics, chosen to reflect various resistance mechanisms. Bacteria were grown in $\mathrm{NB}$ at $37 \mathrm{C}$ for $18 \mathrm{~h}$, diluted in saline and $c .10^{4} \mathrm{cfu}$ inoculated on to paired DST plates containing two concentrations of each antibiotic $(\mu \mathrm{g} / \mathrm{ml})$ : ampicillin 4,32 ; carbenicillin 16.64; cephradine 8,32: cefotaxime 2,16; chloramphenicol 2,8; streptomycin 4,16; gentamicin 1,8; kanamycin 4,16 ; amikacin 8,32 ; tobramycin 2,8 ; tetracyc- line 4,16; sulphamethoxazole 16,64; and trimethoprim 1,8 . Cultures that grew on plates containing both concentrations of an antibiotic were recorded as resistant, those that grew on the lower concentrations only were recorded as moderately resistant and those that grew only on the control plate containing no antibiotic were recorded as sensitive.

Minimum inhibitory concentrations (MICs) of gentamicin were determined similarly on DST containing a series of doubling concentrations of antibiotic. The MIC was the lowest concentration that prevented growth after overnight incubation.

\section{Transfer of gentamicin resistance}

Potential donor strains were tested for sensitivity to nalidixic acid $40 \mu \mathrm{g} / \mathrm{ml}$ and rifampicin $100 \mu \mathrm{g} / \mathrm{ml}$. Sensitive donors were mated with nalidixic acid-resistant recipients and nalidixic acid-resistant donors with rifampicin-resistant recipients by mixing donors and recipients grown in NB for $18 \mathrm{~h}$ in $1: 5$ ratios $(\mathrm{v}: \mathrm{v})$ then incubating statically for a further $6 \mathrm{~h}$ at $37^{\circ} \mathrm{C}$. Dilutions were then plated out and transconjugants selected on DST containing gentamicin $20 \mu \mathrm{g} / \mathrm{ml}$ plus either nalidixic acid $40 \mu \mathrm{g} /$ $\mathrm{ml}$ or rifampicin $100 \mu \mathrm{g} / \mathrm{ml}$ to select against growth of the donor. Plates were incubated for $48 \mathrm{~h}$ at $37^{\circ} \mathrm{C}$. A minimum of 10 clones were re-isolated on the same medium to ensure purity, grown in non-selective medium and tested for their antibiotic sensitivity to determine cotransferred resistances. The frequency of gentamicinresistance transfer was calculated as the number of resistant transconjugants divided by the number of donor organisms. The ability of transconjugants themselves to transfer resistance was tested in a similar manner to determine whether or not plasmids were self-transferable.

\section{Screening for presence of plasmid DNA}

Plasmids were detected by agarose-gel electrophoresis by the method of Birnboim and Doly (1979).

\section{Characterisation of plasmids}

The approximate size of each plasmid was estimated from its migration in agarose gel relative to standards of known size. Plasmids were assigned to incompatibility groups by the methods given in Frost et al. (1982). Plasmid-encoded antibiotic resistances and gentamicin MICs were determined by testing for the resistance which they conferred on $E$. coli $\mathrm{K} 12$ recipients.

\section{Results}

\section{Characterisation of isolates from infections}

The isolation of 37 clinical isolates of gentamicinresistant gram-negative bacilli from 34 patients in a 6-month period was unusual, in that only a single gentamicin-resistant isolate of Citrobacter freundi 
had been detected in the previous 6 months. Several different species and serotypes were identified and these were grouped according to their place and time of isolation (table I). Most were isolated from urine, but three were isolated from sputum, two from wounds and one each from bile and blood. They included 20 Klebsiella isolates, 18 of which were isolated within 1 month of each other. These were subdivided (table I) into $K$. oxytoca and $K$. aerogenes and were further distinguishable by being

Table I. Characterisation of gentamicin-resistant and moderately-resistant bacteria isolated from infections

\begin{tabular}{|c|c|c|c|c|c|}
\hline $\begin{array}{l}\text { Month of } \\
\text { isolation }\end{array}$ & Species & Serotype & Antibiotic resistances* & $\begin{array}{l}\text { Gentamicin } \\
\operatorname{MIC}(\mu \mathrm{g} / \mathrm{ml})\end{array}$ & Source \\
\hline \multicolumn{6}{|l|}{ Ward $A$} \\
\hline Jul. & P. cepacia & $\ldots$ & A Cb Cp C $\mathrm{C}^{\mathrm{m}} \mathrm{G} \mathrm{K} \mathrm{Ak}$ To T Su Tm & 512 & urine \\
\hline Jul. & C. freundi & $\ldots$ & $\mathrm{A} \mathrm{Cb} \mathrm{Cp}{ }^{\mathrm{m}}$ C S G K To T Su Tm & 16 & urine \\
\hline Jul. & $P$. aeruginosa & NT & A CbCpCtx C S G K Ak ${ }^{\mathrm{m}} \mathrm{To}^{\mathrm{m}} \mathrm{T}$ Su Tm & 512 & urine \\
\hline Sept. & $P$. aeruginosa & $\mathrm{O} 1$ & A Cb Cp S G K To T Su Tm ${ }^{m}$ & 512 & bile \\
\hline Oct. & Ent. cloacae & O9 & A Cb Cp C S G K T Su Tm & 16 & blood \\
\hline Oct. & Ent. agglomerans & $\ldots$ & A Cb Cp S G K To T Su Tm ${ }^{\mathrm{m}}$ & 64 & urine \\
\hline Nov. & P. aeruginosa & NT & $\mathrm{A} \mathrm{Cb} \mathrm{Cp} \mathrm{S} \mathrm{G}{ }^{\mathrm{m}} \mathrm{KAk}^{\mathrm{m}} \mathrm{To}^{\mathrm{m}} \mathrm{Su} \mathrm{Tm}$ & 8 & wound \\
\hline Nov. & K. oxytoca & K35 & A Cb Cp ${ }^{m}$ S G K To T Su Tm & 256 & urine \\
\hline Nov. & K. oxytoca & K3 & $\mathrm{A} \mathrm{Cb} \mathrm{Cp^{ \textrm {m } }} \mathrm{CS} \mathrm{G} \mathrm{K} \mathrm{To}^{\mathrm{m}} \mathrm{T} \mathrm{Su} \mathrm{Tm}$ & 32 & urine \\
\hline Nov. & K. oxytoca & K3 & A Cb Cp ${ }^{m}$ C S G K To ${ }^{m}$ T Su Tm & 32 & urine \\
\hline $\begin{array}{l}\text { Nov. } \\
\text { Ward B }\end{array}$ & K. oxytoca & K3 & $\mathrm{A} C b \mathrm{Cp}^{\mathrm{m}} \mathrm{CS} \mathrm{G} \mathrm{K} \mathrm{To}{ }^{\mathrm{m}} \mathrm{T} S \mathrm{Tm}$ & 32 & urine \\
\hline Dec. & $K$. aerogenes & K6 & A Cb Cp ${ }^{m}$ C S G K T Su Tm & 16 & sputum \\
\hline $\begin{array}{l}\text { Dec. } \\
\text { Ward C }\end{array}$ & $P$. aeruginosa & $\mathrm{O} 1$ & $\mathrm{~A} \mathrm{Cb}^{\mathrm{m}} \mathrm{Cp}^{\mathrm{m}}$ C S G K Ak To $\mathrm{T}^{\mathrm{m}} \mathrm{Tm}^{\mathrm{m}}$ & 512 & sputum \\
\hline $\begin{array}{l}\text { Dec. } \\
\text { Ward D }\end{array}$ & $K$. aerogenes & K2 & A Cb Cp ${ }^{m}$ C S G K To $T^{m}$ Su Tm & 32 & urine \\
\hline Jun. & K. oxytoca & NT & A Cb Cp ${ }^{m}$ S G K To $T^{m}$ Su Tm & 128 & urine \\
\hline Oct. & $K$. aerogenes & K68 & A Cb Cp ${ }^{m}$ C S G K To $T^{m} S u T m$ & 32 & urine \\
\hline Nov. & K. oxytoca & K3 & A Cb Cp ${ }^{m}$ C S G K To ${ }^{m}$ T Su Tm & 32 & urine \\
\hline Nov. & K. oxytoca & NT & A Cb Cp ${ }^{m}$ S G K To T Su Tm & 128 & urine \\
\hline Nov. & K. oxytoca & NT & A CB Cp ${ }^{m}$ C S G K Ak ${ }^{m} T^{m} T S u T m$ & 16 & urine \\
\hline Nov. & Ent. agglomerans & $\ldots$ & A Cb Cp C S G K To T Su Tm & 32 & urine \\
\hline Nov. & Ent. agglomerans & $\ldots$ & A Cb Cp C S G K To $\mathrm{T}^{\mathrm{m}} \mathrm{Su} \mathrm{Tm}$ & 32 & urine \\
\hline Nov. & Ent. agglomerans & $\ldots$ & A Cb Cp S G K Ak ${ }^{\mathrm{m}}$ To T Su Tm & 32 & urine \\
\hline Dec. & $K$. aerogenes & $\mathrm{K} 2$ & A Cb Cp ${ }^{m}$ C S G K To $T^{m}$ Su Tm & 32 & urine \\
\hline $\begin{array}{l}\text { Dec. } \\
\text { Ward E }\end{array}$ & K. aerogenes & $\mathrm{K} 2$ & A Cb Cp ${ }^{m}$ C S G K To $T^{m}$ Su Tm & 32 & sputum \\
\hline Sept. & C. freundi & $\ldots$ & A Cb Cp C S G K To T Su Tm & 128 & urine \\
\hline Nov. & K. oxytoca & NT & A Cb Cp ${ }^{m}$ S G K To T Su Tm & 128 & urine \\
\hline Nov. & K. oxytoca & K35 & A Cb Cp ${ }^{m} S$ G K To T Su Tm & 128 & urine \\
\hline Nov. & K. oxytoca & K35 & A Cb Cp ${ }^{m}$ S G K To T Su Tm & 256 & urine \\
\hline Nov. & Pr. morgani & $\ldots$ & A Cb Cp C S G K Ak To T ${ }^{\mathrm{m}} \mathrm{Tm}$ & 64 & urine \\
\hline Nov. & $K$. aerogenes & K68 & A Cb Cp ${ }^{\mathrm{m}} \mathrm{CS} \mathrm{G} \mathrm{K} \mathrm{To} \mathrm{T}^{\mathrm{m}} \mathrm{Su} \mathrm{Tm}$ & 32 & urine \\
\hline Nov. & Ent. agglomerans & $\ldots$ & $A^{m} C p^{m} S^{m} G^{m} K^{m} A k^{m} T^{m} T^{m} S^{m}$ & 8 & urine \\
\hline Dec. & $K$. aerogenes & $\mathrm{K} 2$ & $\mathrm{~A} \mathrm{CbCp}{ }^{\mathrm{m}} \mathrm{C} \mathrm{S} \mathrm{G} \mathrm{K} \mathrm{To} \mathrm{T} \mathrm{T}^{\mathrm{m}} \mathrm{Su} \mathrm{Tm}$ & 32 & urine \\
\hline Dec. & K. aerogenes & $\mathrm{K} 2$ & $\mathrm{~A} \mathrm{Cb} \mathrm{Cp}{ }^{\mathrm{m}} \mathrm{CS} \mathrm{G} \mathrm{K} \mathrm{To} \mathrm{T}{ }^{\mathrm{m}} \mathrm{Su} \mathrm{Tm}$ & 32 & urine \\
\hline $\begin{array}{l}\text { Dec. } \\
\text { Ward F }\end{array}$ & K. oxytoca & NT & A Cb Cp ${ }^{m} C^{m}$ S G K Ak To T $T^{m}$ & 128 & urine \\
\hline $\begin{array}{l}\text { Nov. } \\
\text { Ward G }\end{array}$ & Pr. morgani & $\cdots$ & $\mathrm{Cp}^{\mathrm{m}}$ C S G K Ak To T Su $\mathrm{Tm}^{\mathrm{m}}$ & 64 & urine \\
\hline $\begin{array}{l}\text { Oct. } \\
\text { Ward H }\end{array}$ & Pr. mirabilis & $\ldots$ & A Cb Cp C S G K Ak ${ }^{m}$ To T Su Tm & 128 & urine \\
\hline Oct. & Proteus sp. & $\ldots$ & $\mathrm{Cp}^{\mathrm{m}}$ C S G K $\mathrm{K}^{\mathrm{m}} \mathrm{Ak}^{\mathrm{m}}$ To T Su${ }^{\mathrm{m}} \mathrm{Tm}^{\mathrm{m}}$ & 16 & wound \\
\hline
\end{tabular}


K-serotype 2, 3, 6, 35, 68 or non-typable (NT). Some evidence of cross infection was suggested, in that three patients in ward A and one in ward D were infected by a $K$. oxytoca type-K 3 strain and the latter patient had been transferred to ward $D$ from ward $\mathrm{A}$; two patients in ward $\mathrm{E}$ and one in ward $\mathrm{A}$ were infected by a $K$. oxytoca type-K 35 strain, but there was no record of transfer of these patients between wards; one patient in ward $D$ and one in ward $\mathrm{E}$ were infected by a $K$. aerogenes type-K68 strain and the latter patient had been transferred from ward $D$; and two patients in ward $E$, two in ward $\mathrm{D}$ and one in ward $\mathrm{C}$ were infected by a $K$. aerogenes type-K 2 strain and the ward $C$ patient and one of the ward $E$ patients had been transferred from ward D. Cross infection did not, however, explain other gentamicin-resistant infections caused by a variety of organisms. All isolates were resistant to gentamicin $8 \mu \mathrm{g} / \mathrm{ml}$ at least, but MICs were in the range $16-256 \mu \mathrm{g} / \mathrm{ml}$ amongst Klebsiella isolates and were highest in $P$. aeruginosa and $P$. cepacia isolates. Multi-resistance was common, notably to other aminoglycosides and trimethoprim, though few isolates were resistant to amikacin and only one $P$. aeruginosa isolate was resisant to the thirdgeneration cephalosporin, cefotaxime. Results are detailed in table I. Some similarities in resistance pattern were noted and, therefore, inter- and intrageneric relationships were explored by plasmid analysis.

Gentamicin-resistance plasmids in infecting organisms

Klebsiella isolates accounted for more than half the clinical gentamicin-resistant isolates and these were studied further. They were classified, tested for their ability to transfer gentamicin resistance to $E$. coli $\mathrm{K} 12$ and screened for the presence of plasmid DNA. Results are given in table II. Antibioticresistance pattern and plasmid content were remarkably similar amongst serologically related isolates and differed amongst non-typable isolates.

$K$. oxytoca serotype-K3, isolated from four different patients and two different wards, were further related by their resistance to the same set of antibiotics and. with one exception in which the smallest plasmid was missing, by their carriage of four similar-sized plasmids. Transferable gentamicine resistance was present in all and associated with only one of the plasmids (mol. wt $70 \times 10^{6}$ ). This was transferable at a moderate frequency of $10^{-4}$ to $10^{-5}$ and encoded further resistances ( $\mathrm{A} \mathrm{Cb} \mathrm{C} \mathrm{S} \mathrm{G} \mathrm{K}$ $\left.\mathrm{To}^{\mathrm{m}} \mathrm{T} \mathrm{Su} \mathrm{Tm}\right)$. It was not, however, capable of selftransfer.

In contrast, $K$. oxytoca serotype-K 35 isolates, though similar in their antibiotic resistances, carried a pair of large plasmids which differed slightly in size between isolates, and none transferred gentamicin resistance.

Amongst the heterogeneous group of non-typable $K$. oxytoca, plasmid carriage differed. Only one isolate transferred gentamicin resistance and this was encoded by a plasmid of mol. wt $70 \times 10^{6}$, further encoding a similar set of resistances to that encoded by the same sized plasmid carried by serotype- 3 isolates, excepting low-level tobramycin resistance.

$K$. aerogenes serotype-K68 strains were isolated from different wards but were resistant to the same set of antibiotics and two of the three plasmids demonstrated in each isolate were of common size. In both, gentamicin resistance was transferable and encoded by $125 \times 10^{6}-\mathrm{mol}$. wt plasmids. Two plasmid-encoded antibiotic-resistance patterns were identified- one common to both isolates, the other present only in the isolate from ward D. Lack of tetracycline resistance determinants allowed us to characterise the plasmids further according to their incompatibility by use of tetracycline-resistance plasmids of known incompatibility groups and all three were related in belonging to incompatibility group C.

$K$. aerogenes serotype-K2 strains were isolated from five patients on three wards, but were resistant to the same set of antibiotics. Each carried three plasmids whose sizes were common to four isolates and only one plasmid differed in the fifth. In each isolate gentamicin resistance was transferable and encoded by a $125 \times 10^{6}-\mathrm{mol}$. wt plasmid and this further encoded resistance to the same nine antibiotics ( $\mathrm{A} \mathrm{Cb} \mathrm{Cm}$ S G K To Su Tm) encoded by the same-sized plasmid (D) isolated from serotype-K 68 isolates. Similarly, in three of the five isolates the plasmid belonged to incompatibility group $\mathrm{C}$.

The single $K$. aerogenes serotype- 6 isolate differed from the other $K$. aerogenes isolates not only in being isolated from ward $\mathrm{B}$, but also in its pattern of antibiotic resistances, failure to transfer gentamicin resistance and lack of detectable plasmid DNA.

To determine whether these gentamicin plasmids occurred in other gram-negative bacteria isolated from infections, isolates with the same antibioticresistance patterns as those encoded by the plasmids were screened for transferability of gentamicin resistance and plasmid content. Table II shows that from seven such isolates, plasmids, 1-7 in number and $(1 \cdot 2-125) \times 10^{6} \mathrm{~mol}$. wt, were detected in five but transferable gentamicin resistance was detected only in one. In this Enterobacter agglomerans isolate, transfer of gentamicin resistance was 
Table II. Characterisation of plasmids in infecting organisms

\begin{tabular}{|c|c|c|c|c|c|c|}
\hline \multirow[b]{2}{*}{$\begin{array}{l}\text { Isolate } \\
\text { and source }\end{array}$} & \multirow{2}{*}{$\begin{array}{c}\text { Approximate } \\
\text { mol. wt }\left(10^{6}\right) \text { of } \\
\text { plasmids detected }\end{array}$} & \multirow{2}{*}{$\begin{array}{l}\text { Frequency of } \\
\text { gentamicin } \\
\text { resistance } \\
\text { transfer* }\end{array}$} & \multicolumn{4}{|c|}{ Gentamicin resistance plasmid } \\
\hline & & & $\begin{array}{l}\text { Antibiotic resistances } \\
\text { cotransferred } \dagger\end{array}$ & $\begin{array}{l}\text { mol. wt } \\
\left(10^{6}\right)\end{array}$ & $\begin{array}{l}\text { incompatibility } \\
\text { group }\end{array}$ & code \\
\hline \multicolumn{7}{|c|}{ K. oxytoca, $\mathrm{K} 3$} \\
\hline Ward A & 957065 & $6.0 \times 10^{-5}$ & \multirow{4}{*}{$\mathrm{ACbCSGK} \mathrm{To}{ }^{\mathrm{m}} \mathrm{TSu} \mathrm{Tm}$} & \multirow{4}{*}{70} & \multirow{4}{*}{ - } & \multirow{4}{*}{ A } \\
\hline Ward A & $9570651 \cdot 5$ & $1.0 \times 10^{-4}$ & & & & \\
\hline Ward A & $9570651 \cdot 5$ & $6.0 \times 10^{-4}$ & & & & \\
\hline Ward D & $9570651 \cdot 5$ & $\left.4.0 \times 10^{-5}\right]$ & & & & \\
\hline \multicolumn{7}{|c|}{ K. oytoca, $\mathrm{K} 35$} \\
\hline $\begin{array}{l}\text { Ward A } \\
\text { Ward E }\end{array}$ & 10070 & $\begin{array}{l}\mathrm{nt} \\
\mathrm{nt}\end{array}$ & & & & \\
\hline Ward E & 11085 & $\mathrm{nt}$ & & & & \\
\hline \multicolumn{7}{|c|}{ K. oxytoca, NT } \\
\hline Ward D & NONE & $\mathrm{nt}$ & & & & \\
\hline Ward D & 160105 & nt & & & & \\
\hline Ward D & 110701.81 .5 & $1.6 \times 10^{-5}$ & A Cb C S G K T Su Tm & 70 & - & B \\
\hline Ward E & 140100 & nt & & & & \\
\hline Ward E & 140100 & $\mathrm{nt}$ & & & & \\
\hline \multicolumn{7}{|c|}{$K$. aerogenes, $\mathrm{K} 68$} \\
\hline Ward D & $1701255 \cdot 8$ & $3.3 \times 10^{-4}$ & $\left\{\begin{array}{l}\text { A Cb C G K To Su } \\
\text { C Cb } \text { C }^{m} S G K T o S u T m\end{array}\right.$ & $\begin{array}{l}125 \\
125\end{array}$ & $\mathrm{C}$ & C \\
\hline Ward E & 1251005.8 & $1.7 \times 10^{-6}$ & $\mathrm{~A} \mathrm{Cb} \mathrm{C}^{\mathrm{m}} \mathrm{S} \mathrm{G}$ K To Su Tm & 125 & $\mathrm{C}$ & $\mathrm{D}$ \\
\hline \multicolumn{7}{|c|}{ K. aerogenes, $\mathrm{K} 2$} \\
\hline Ward C & 1701255.8 & $8.3 \times 10^{-6}$ & & & $\mathrm{C}$ & D \\
\hline Ward D & $1251005 \cdot 8$ & $2.4 \times 10^{-4}$ & & & $\mathrm{C}$ & D \\
\hline Ward D & $1251005 \cdot 8$ & $2.6 \times 10^{-6}$ & $\mathrm{~A} \mathrm{Cb} \mathrm{C}^{\mathrm{m}} \mathrm{S} \mathrm{G} \mathrm{K}$ To Su Tm & 125 & $?$ & E \\
\hline Ward E & $1251005 \cdot 8$ & $8.9 \times 10^{-5}$ & & & $\mathrm{C}$ & D \\
\hline Ward E & $1251005 \cdot 8$ & $\left.3.2 \times 10^{-6}\right]$ & & & $?$ & $\mathrm{E}$ \\
\hline \multicolumn{7}{|c|}{ K. aerogenes, $\mathrm{K} 6$} \\
\hline Ward B & NONE & $\mathrm{nt}$ & & & & \\
\hline \multicolumn{7}{|c|}{$P$. aeruginosa, $\mathrm{NT}$} \\
\hline Ward A & 15 & $\mathrm{nt}$ & & & & \\
\hline \multicolumn{7}{|l|}{ C. freundi } \\
\hline Ward A & $1204520181371 \cdot 8$ & nt & & & & \\
\hline \multirow{2}{*}{\multicolumn{7}{|c|}{$P$. cepacia }} \\
\hline & & & & & & \\
\hline \multirow{2}{*}{\multicolumn{7}{|c|}{ Ent. agglomerans }} \\
\hline & & & & & & \\
\hline Ward D & $125110705 \cdot 0$ & $1.0 \times 10^{-6}$ & A Cb C ${ }^{m}$ S G K To Su Tm & 110 & $\mathrm{C}$ & $\mathrm{F}$ \\
\hline Ward D & $1251105 \cdot 0$ & $\mathrm{nt}$ & & & & \\
\hline \multicolumn{7}{|c|}{ Pr. mirabilis } \\
\hline Ward G & $1 \cdot 2$ & $\mathrm{nt}$ & & & & \\
\hline
\end{tabular}

NT = non-typable; $n t=$ no transfer

* Frequency of transfer is the number of resistant transconjugants divided by the number of donor organisms.

+ See footnote to table $I$.

accompanied by transfer of a plasmid (F), mol. wt $110 \times 10^{6}$, which further encoded resistance to the same set of antibiotics and belonged to the same incompatibility group as the $125 \times 10^{6}-\mathrm{mol}$. wt plasmid (D) previously described in $K$. aerogenes serotypes 2 and 68 .

In summary, six gentamicin-resistance plasmids were distinguished in infecting organisms and all conferred resistance to a core of five antimicrobials (A Cb G K Su). One plasmid (A) of mol. wt $70 \times 10^{6}$, encoded resistance to A Cb C S G K To ${ }^{\mathrm{m}} \mathrm{T}$ Su Tm; the second (B) was also of mol. wt $70 \times 10^{6}$, but coded for resistance to A Cb C S G K T Su Tm; the third (C) was of mol. wt $125 \times 10^{6}$ encoding resistance to A Cb C G K To Su; the fourth (D) and fifth (E) were also of mol. wt $125 \times 10^{6}$ but coded for resistance to $\mathrm{A} \mathrm{Cb} \mathrm{Cm} S \mathrm{~S} \mathrm{~K}$ To Su Tm and whereas $\mathrm{D}$ belonged to incompatibility group $\mathrm{C}, \mathrm{E}$ did not; and the sixth plasmid (F) was of mol. wt $110 \times 10^{6}$ encoding resistance to $\mathrm{A} \mathrm{Cb} \mathrm{C}^{\mathrm{m}} \mathrm{S} \mathrm{G} \mathrm{K} \mathrm{To} \mathrm{Su} \mathrm{Tm}$ and belonging to incompatibility group $\mathrm{C}$. No plasmid was self-transferable. Plasmid A was identi- 
Table III. Characterisation of gentamicin-resistant and moderately-resistant bacteria isolated from ward $\mathrm{A}$

\begin{tabular}{|c|c|c|c|c|}
\hline Isolate & Serotype & Antibiotic resistances* & $\begin{array}{l}\text { Gentamicin } \\
\operatorname{MIC}(\mu \mathrm{g} / \mathrm{ml})\end{array}$ & Source \\
\hline \multicolumn{5}{|l|}{ Inanimate environment } \\
\hline Acinetobacter inoffi & $\ldots$ & $A^{m} C_{p}^{m} C S G K^{m} T_{o}^{m} T S u T m^{m}$ & 128 & kitchen sink \\
\hline Aeromonas sp. & $\ldots$ & $C p^{m} S G^{m} K A k^{m} T_{o}^{m} T^{m} S u T m$ & 4 & mop \\
\hline Aeromonas sp. & & $A^{m} C p^{m} C^{m} S G^{m} K A k^{m} T_{o}^{m} T_{S u^{m}}$ & 4 & kitchen sink \\
\hline 4. hydrophila & $\cdots$ & A CBCpS G ${ }^{m}$ K Ak $^{m} T_{0}^{m} T^{m} S u T m^{m}$ & 4 & kitchen sink \\
\hline 4. hudrophila & & $A C b C p S G^{m} K A k^{m}$ To $T^{m} S^{m}$ & 2 & flower vase (3) \\
\hline Eni sloacas & 027 & $A^{m} C p^{m} S G K A k^{m} T_{o}^{m} T^{m} S u T m$ & 16 & clean room sink \\
\hline Ent. cloacae & 027 & 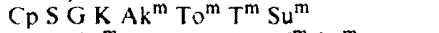 & 16 & clean room sink \\
\hline Ent. cloacate & O9 & $\mathrm{ACbCp}{ }^{\mathrm{m}} \mathrm{SGK}$ Ak To $\mathrm{T}^{\mathrm{m}} \mathrm{Su}^{\mathrm{m}}$ & 16 & ward hand basin ( 1 ) \\
\hline Ent toucue & O9 & $A^{m} C p^{m} S G^{m} K A k^{m} T o_{o}^{m} T^{m} S u^{m}$ & 8 & w.c. (2) \\
\hline Ent loacat & 09 & $C p^{m} S G K A k^{m} T_{o}^{m} T^{m} S u$ & 16 & bed pan washer \\
\hline K. arvoca & $\mathrm{NT}$ & $A C b^{m} C p^{m} C^{m} S G K A k$ To $T^{m} T^{m}$ & 128 & bathroom (B) bath \\
\hline K. axyora & K68 & A Cb Cp $C^{m}$ S G K Ak To T Su Tm & 32 & mop \\
\hline P. acidotorans & $\ldots$ & ACbCp C S G K Ak To $T^{m} T^{m}$ & 32 & clean room hand basin \\
\hline P. acidotorans & $\ldots$ & A CbCp ${ }^{m}$ C S G K To ${ }^{m}$ T Su Tm & 512 & flower vase (1) \\
\hline P. acidotorans & $\ldots$ & ACbC $p^{m} C S G k T o^{m} T S u T m$ & 32 & flower vase (2) \\
\hline P. acidotorans & & 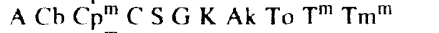 & 256 & bathroom ( $B$ ) hand basin (1) \\
\hline P. acidotorans & $\ldots$ & A CbCp ${ }^{m}$ S K K To T Su Tm & 256 & bathroom (B) hand basin (1) \\
\hline P. acidoloruns & $\ldots$ & A Cb Cp ${ }^{m}$ G K To T Su Tm & 256 & sucker \\
\hline P. acidovoruns & $\ldots$ & A CbCpCtx C S G K Ak To T Su Tm & 512 & sucker \\
\hline P. acidotorans & $\ldots$ & A CbCp ${ }^{m} C S G K A k^{m}$ To $T^{m}$ Su Tm & 64 & ward hand basin (2) \\
\hline P. widotorans & $\ldots$ & A CbCpCSGK To T Su Tm & 256 & flower vase (3) \\
\hline P. acidororans & $\ldots$ & A CbCpCSGK Tom T Su Tm & 128 & side-ward hand basin \\
\hline P. aeruginosa & O10 & A CbCp ${ }^{m}$ SGK To T Su ${ }^{m} \mathrm{Tm}$ & $\$ 12$ & w.c. (2) \\
\hline P. aeruginosa & $\mathrm{O} 10$ & $A^{m} C^{m} C p C i x^{m} C S^{m} G^{m} K T S u^{m} T m$ & 2 & ward hand basin (2) \\
\hline$P$. aeruginosa & OI & A CbCp ${ }^{m} C S G K T o^{m} T S u T m$ & 256 & bed pan washer \\
\hline$P$. aeruginosa & $\mathrm{Ol}$ & 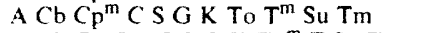 & 512 & washroom sink \\
\hline P. aeruginosa & $\mathrm{OI}$ & A CbCp Ctx CS GK To ${ }^{m}$ T Su Tm & 512 & washroom sink \\
\hline$P$ aeruginosa & 01 & ACbCpCuCSGK Ak ${ }^{m} \mathrm{To}^{\mathrm{m}} \mathrm{TSu} \mathrm{Tm}$ & 512 & hopper \\
\hline P. aeruginosa & $\mathrm{OI}$ & A CbCpCtx CSGK To ${ }^{m} T_{S u} T m$ & 512 & hopper \\
\hline P. aeruginosa & $\mathrm{OI}$ & A CbCpCix C S G K To ${ }^{m}$ T Su Tm & 512 & soaking elastic stockings \\
\hline P. alkaligenes & $\ldots$ & $A^{m} C b C p C t x^{m} C^{m} S^{m} G^{m} K$ To Su & 4 & w.c. (1) \\
\hline P. maltophitia & & $\mathrm{A}^{\mathrm{m}} \mathrm{Cp} \operatorname{Ctx} \mathrm{CSGKAk}$ To T So ${ }^{\mathrm{m}} \mathrm{Tm}$ & 16 & clean room hand basin \\
\hline P. maltophilia & $\ldots$ & A Cp Cix ${ }^{m}$ S GKAk To T Su Tm & 16 & clean room sink \\
\hline P. malophilia & $\ldots$ & ACpCix $C^{m} S G K A k$ To T Su Tm & 16 & bathroom $(A)$ bath \\
\hline P. maltophilia & $\ldots$ & 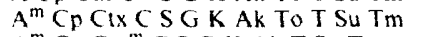 & 32 & flower vase (2) \\
\hline P. maltophilia & $\ldots$ & $A^{m} C p C i x^{m} C S G K A k T S u T m$ & 256 & bathroom (B) hand basin (2) \\
\hline P. maltophilia & $\ldots$ & CpCSGK Ak To T Su Tm & 16 & bathroom (B) sink \\
\hline P. malnophilia & $\ldots$ & CpCSGKAk To T Su Tm & 128 & sucker \\
\hline P. maltophilia & & $C_{p} C_{t x}{ }^{m}$ S G K Ak To Su Tm & 128 & mop \\
\hline P. maltophilia & $\ldots$ & $A^{m} C_{p} C x^{m} C^{m}$ S G K Ak To T Tm & 32 & ward hand basin (2) \\
\hline P. maltophilia & $\ldots$ & A C ${ }^{m} \mathrm{~S} G \mathrm{KAk}$ To & 128 & side-ward hand basin \\
\hline P. pseudoalkaligenes & $\ldots$ & A Ch $C_{p} C_{1 x^{m}} C S G$ K To Su Tm & 16 & washroom sink \\
\hline P. pseudoalkaligenes & $\ldots$ & A CbCp Cix ${ }^{m}$ S G k To Su Tm ${ }^{m}$ & 16 & soaking elastic stockings \\
\hline P. putida & $\ldots$ & A CbCpCtx C S G T Su Tm & 16 & sucker \\
\hline \multicolumn{5}{|c|}{ ( } \\
\hline C. freundi & $\cdots$ & $C p^{m} C x^{m} C^{m} S^{m} G^{m} K^{m} A k^{m} T_{o}^{m} S u^{m}$ & 4 & faeces, staff I \\
\hline E. coli & & $A C p^{m} C^{m} S G K A k$ To $T^{m} T_{m}^{m}$ & 16 & faeces, staff 2 \\
\hline E. coli & O92 & A CbCp Cix C S K To ${ }^{m}$ T Su Tm & 16 & faeces, staff 3 \\
\hline E. coni & $\ldots$ & $C p^{m} S G K A k^{m} T o^{m} T^{m} S u^{m}$ & 16 & faeces, staff 4 \\
\hline E. coll & $\ldots$ & $A^{m} C p^{m} S^{m} G^{m} K^{m} A k^{m} T o^{m} T^{m} S u^{m}$ & 2 & faeces, staff 5 \\
\hline E. coll & $\ldots$ & A CbCpS G ${ }^{m} \mathrm{Ak}^{\mathrm{m}} \mathrm{To}^{\mathrm{m}} \mathrm{T}^{\mathrm{m}} \mathrm{Su}$ & 4 & faeces, staff 6 \\
\hline E. coli & $\ldots$ & $C p^{m} S^{m} G^{m} K^{m} T_{o}^{m} T^{m} S^{m}$ & 2 & faeces, staff 7 \\
\hline E. coli & & $A C b C p^{m} C^{m} G^{m} K A k^{m} T_{o}^{m} T S u T m$ & 4 & faeces, staff 8 \\
\hline E. coll & $\ldots$ & 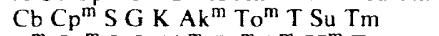 & 16 & faeces, staff 9 \\
\hline E. coli & $\cdots$ & $A^{m} C_{p}^{m} S G A k^{m} T_{o}^{m} T^{m} S 7^{m} T m$ & 16 & faeces, staff 10 \\
\hline \multicolumn{5}{|l|}{ Patients } \\
\hline E. coli & $\ldots$ & $A C^{\mathrm{m}} \mathrm{SGKAk}$ To $\mathrm{T}^{\mathrm{m}}$ & 16 & faeces, patient 1 \\
\hline E. coli & $\ldots$ & $A C^{\mathrm{m}} \mathrm{S} G \mathrm{~K}$ Ak To $\mathrm{T}^{\mathrm{m}}$ & 16 & faeces, patient 2 \\
\hline E. coli & & A CbCpCix C G K To ${ }^{m}$ T Su Tm & 16 & faeces, patient 3 \\
\hline E wh & $\mathrm{O} 77$ & A CbCpCix C S K To ${ }^{m}$ T Su Tm & 16 & faeces, patien 4 \\
\hline E.coli & NT & A CbCp Cix C S G K To ${ }^{m}$ T Su Tm & 16 & faeces, patient 5 \\
\hline E.coli & $\ldots$ & $C p^{m} C^{m} S G^{m} K^{m} A k^{m} T o^{m} T S u^{m}$ & 2 & faeces, patient 5 \\
\hline E. coli & $\ldots$ & $\mathrm{Cp}^{\mathrm{m}} \mathrm{GKAk^{ \textrm {m } }}$ To $\mathrm{T}^{\mathrm{m}} \mathrm{Su}^{\mathrm{m}}$ & 16 & faeces, patient 6 \\
\hline E. coli & $\ldots$ & $A^{m} C p^{m} C^{m} S^{m} G^{m} K^{m} A k^{m} T_{o}^{m} T^{m} S u^{m}$ & 4 & faeces, patient 7 \\
\hline E. coll & $\ldots$ & $A C b C p^{m} S G K A k^{m} T_{o}^{m} T S u$ & 16 & faeces. patient 8 \\
\hline E. colli & & $A^{m} C p^{m} S^{m} G^{m} K A k^{m} T o^{m} T^{m} S u^{m}$ & 4 & faeces, patient 9 \\
\hline E. coli & 019 & $A C b C p^{m} C S G K T o^{m} T S u T m$ & 32 & faeces. patient 10 \\
\hline K. axyroca & K68 & A Cb Cp C $\mathrm{S} G$ K Ak To T Su Tm & 32 & faeces, patient 6 \\
\hline P. aeruginosa & $\mathrm{OI}$ & ACbCpCixCSGKAk ${ }^{m} \mathrm{To}^{\mathrm{m}} \mathrm{TSu} \mathrm{Tm}$ & 512 & faeces, patient 10 \\
\hline
\end{tabular}

NT $=$ non - typable

* See footnote to table 1 
fied in $K$. oxytoca serotype-K 3 , plasmid B in a nontypable $K$. oxytoca, plasmid $\mathrm{C}$ in a single $K$. aerogenes serotype $\mathrm{K} 68$, plasmid D in $K$. aerogenes serotypes $\mathrm{K} 2$ and $\mathrm{K} 68$, plasmid $\mathrm{E}$ in $K$. aerogenes serotype $\mathrm{K} 2$ and plasmid $\mathrm{F}$ in a single Ent. agglomerans strain. Thus, plasmid A was isolated from ward $\mathrm{A}$, plasmid D from ward C, plasmids D and $\mathrm{E}$ from ward $\mathrm{E}$ and all six plasmids were isolated from ward D. Ward A was investigated further.

\section{Characterisation of isolates from ward $A$}

Characteristics of gentamicin-resistant and moderately-resistant gram-negative bacteria from ward A are given in table III. Their sources in the inanimate environment were, as expected, wet areas, e.g., sinks and baths, and none were obtained from medicines, creams, air fresheners, detergents, soap, sand buckets or food. Representatives of five genera-Acinetobacter, Aeromonas, Enterobacter, Klebsiella and Pseudomonas-renowned for their ability to colonise warm moist places, were identified. Their gentamicin MICs were in the range 2$512 \mu \mathrm{g} / \mathrm{ml}$. The faecal sources were in 10 of the 16 patients and 10 of the 16 members of staff. Isolates were mostly $E$. coli, plus $K$. oxytoca from patient no. 6, $P$. aeruginosa from patient no. 10 and $C$. freundi from staff no. 1. Their gentamicin MICs were in the range $2-512 \mu \mathrm{g} / \mathrm{ml}$. Amongst the $20 \mathrm{E}$. coli isolates, $13 \mathrm{had}$ gentamicin MICs exceeding $8 \mu \mathrm{g} / \mathrm{ml}$; additional multi-resistance was a common characteristic and four strains were resistant to all 12 antimicrobials tested, including one third-generation cephalosporin (cefotaxime). A comparison of data (tables I and III) shows that none of the strains causing infections resembled those isolated from either the inanimate environment or the gastro-intestinal tracts of staff and patients of ward A.

Gentamicin-resistance plasmids in staff, patients and environmental isolates of ward $A$

Isolates whose antibiotic-resistance patterns incorporated those encoded by plasmids from infecting organisms were examined further. Of 16 such isolates, plasmids were detected in nine isolates and gentamicin-resistance transferability in three (table IV). Transfer of gentamicin resistance was associated with transfer of $70 \times 10^{6}-\mathrm{mol}$. wt plasmids encoding resistance to the same set of antibiotics as the previously described $70 \times 10^{6}$-mol. wt plasmids A and B. Plasmid A was detected in $K$. oxytoca serotype $\mathrm{K} 68$ isolated from a mop and plasmid B was detected in the faeces of two patients in $E$. coli serotype $\mathrm{O} 19$ and $K$. oxytoca serotype
K68. The occurrence of plasmids in $E$. coli from patient 4 , which were of similar size to those (A, B and $F$ ) in infecting organisms, prompted us to investigate further. In a tri-parental cross involving the broad-host-range plasmid RP1, gentamicin resistance was mobilised and shown to be associated with transfer of a $110 \times 10^{6}$-mol. wt plasmid which further encoded resistance to the same set of antibiotics and belonged to the same incompatibility group $\mathrm{C}$ as the previously described $110 \times 10^{6}$. mol. wt plasmid (F) detected in an Ent. agglomerans isolated from ward $\mathrm{D}$.

\section{Discussion}

Characterisation of isolates from infections and from ward A did not suggest the existence of a reservoir of gentamicin-resistant infecting strains within the hospital environment. The level of gentamicin resistance and other resistances in the environmental isolates was higher than would be expected from those species, with the possible exception of $P$. acidovorans. However, many of the species isolated are not normally regarded as primary hospital pathogens and therefore the multiple resistances observed and the levels of gentamicin resistance would not normally be regarded as cause for concern, unless they were plasmid encoded and capable of transfer to more pathogenic species. Plasmid transfer of resistance is probably normally a rarer event than cross infection involving a resistant strain, but though the frequency of plasmid transfer is probably not increased by antibiotic selection pressures within the hospital environment, survival of resistant recipients is greatly enhanced. Concern is less where strains merely act as "dead end" carriers of plasmids, and are incapable of transferring them, as for example the $E$. coli $\mathrm{O} 20$ isolated from patient 4 , but increases with the realisation that, with the acquisition of a transfer factor as was demonstrated by insertion of another plasmid (RP1) into the donor strain, the resistance plasmid may then become transferable. In this study, six plasmids encoding gentamicin resistance, A B C D E and F, were identified amongst infecting organisms. They were not confined to a particular ward, nor did they owe their presence to that of a particular host serotype, species or genus. In $K$. oxytoca, plasmid A was detected in the different serotypes $\mathrm{K} 68$ and $\mathrm{K} 3$ and in $K$. aerogenes, plasmid $D$ in serotypes $\mathrm{K} 2$ and $\mathrm{K} 68$. Plasmid $\mathrm{B}$ was detected in different genera in $E$. coli $\mathrm{O} 19, K$. oxytoca $\mathrm{K} 68$ and $K$. oxytoca NT.

Having identified transmissable gentamicin-resistance plasmids in infecting organisms, we ques- 
Table IV. Characterisation of plasmids in isolates from ward A

\begin{tabular}{|c|c|c|c|c|c|c|c|}
\hline \multirow[b]{2}{*}{ Source } & \multirow[b]{2}{*}{ Isolate } & \multirow[b]{2}{*}{ Serotype } & \multirow[b]{2}{*}{$\begin{array}{c}\text { Mol. wt }\left(10^{6}\right) \\
\text { of plasmids detected }\end{array}$} & \multirow[b]{2}{*}{$\begin{array}{l}\text { Frequency of } \\
\text { gentamicin } \\
\text { resistance } \\
\text { transfer* }\end{array}$} & \multicolumn{3}{|c|}{ Transferable gentamicin resistance plasmid } \\
\hline & & & & & $\begin{array}{c}\text { antibiotic } \\
\text { resistances } \\
\text { co-transferred* }\end{array}$ & $\begin{array}{l}\text { mol.wt } \\
\left(10^{6}\right)\end{array}$ & $\begin{array}{c}\text { gentamicin } \\
\text { MIC (mg L) } \\
\text { conferred }\end{array}$ \\
\hline \multicolumn{8}{|c|}{ Inanimate environment } \\
\hline Mop & K. oxytoca & K68 & 95702 & $2.6 \times 10^{-1}$ & A CbCSGK Tom ${ }^{m}$ Su Tm & 70 & 64 \\
\hline WC2 (2) & $P$. aeruginosa & 010 & 5614 & $\mathrm{nt}$ & & & \\
\hline \multicolumn{8}{|c|}{ Staff } \\
\hline 3 & E. coli & 092 & $601 \cdot 8$ & nt & & & \\
\hline \multicolumn{8}{|l|}{ Patients } \\
\hline 3 & E. coli & 077 & 953 & nt & & & \\
\hline 4 & E. coli & $\mathrm{O} 20$ & 110702.71 .8 & $\mathrm{nt}$ & & & \\
\hline 5 & E. coli & NT & 3317 & $\mathrm{nt}$ & & & \\
\hline 10 & E. coli & 019 & 9570162.21 .6 & $2.5 \times 10^{-4}$ & A CbC S G K T Su Tm & 70 & 64 \\
\hline 6 & K. oxvtoca & K68 & 957065 & $3.0 \times 10^{-5}$ & A Cb C S G K T Su Tm & 70 & 128 \\
\hline 10 & P. aeruginosa & $\mathrm{O} 1$ & 563714 & nt & & & \\
\hline
\end{tabular}

NT--non-typable; nt-no transfer

* See footnotes to tables I and II.

tioned whether these plasmids had an identifiable source in the ward environment. although the organisms themselves did not. Plasmid A was detected in the ward environment, i.e., in the isolate from a mop on ward $\mathrm{A}$, and also in a different strain infecting three patients on ward $A$ and one on ward D. Plasmid spread to ward D was probably via transfer of a patient carrying the infecting host strain from ward A to ward D. Plasmid B was detected on ward $\mathrm{A}$, being present in two distinct organisms, K. oxvtoca $\mathrm{K} 68$ and $E$. coli O19, carried in the gastro-intestinal tract of two patients; it was not in isolates from infections on ward $A$ but was found in an infection on ward D caused by a nontypable $K$. oxvtoca strain. No link was discovered for this, but the small difference, i.e., low level tobramycin resistance, between plasmids $\mathrm{A}$ and $\mathrm{B}$ may indicate that they are related and may partly explain some of the associations observed. Plasmid $\mathrm{F}$ was detected on ward $\mathrm{A}$ and was carried by a strain of $E$. coli present in the gastro-intestinal tract of one of the patients. It was not isolated from infections on ward A but was isolated from an infection on ward D caused by a different organism.

\section{REFERENCES}

Anderson J D. Gillespie W A, Richmond M H 1973 Chemotherapy and antibiotic-resistance transfer between enterobacteria in the human gastro-intestinal tract. Journal of Medical Microbiology 6:461-473.

Birnboim H C. Doly J 1979 A rapid alkaline extraction procedure for screening recombinant plasmid DNA. Nucleic Acids Research 7:1513 1523.
Ent. agglomerans. Plasmids C, D and E were detected neither in the environment nor in infections occurring on ward $\mathrm{A}$. There thus appeared to be environmental reservoirs, both in the inanimate environment and in patients, for some but not all plasmids implicated in gentamicin-resistant infections and the reservoir might well comprise an organism different from the infecting strain. No environmental site for plasmid transfer was located, but it was interesting to note that plasmid D was clearly identified in two different serotypes of $K$. aerogenes, $\mathrm{K} 2$ and $\mathrm{K} 68$, isolated from the urine of a single infected patient on ward $\mathrm{E}$.

We thank colleagues at the Central Public Health Laboratory, Colindale, London, Mr R. Gross, Dr J. Threlfall and Dr G. Smith (Division of Enteric Pathogens), for typing E. coli strains, for the gift of plasmid marker strains and for valuable advice, and $\mathrm{Mr} \mathrm{M}$. Gaston, Dr T. Pitt and $\mathrm{Mr} \mathrm{H}$. Todd (Division of Hospital Infection), for speciation of environmental isolates and typing of $P$. aeruginosa and Enterobacter isolates and we thank Dr P. Mortimer (Coventry, PHL), for typing Klebsiella strains. We are further grateful to $\mathrm{Mr} \mathbf{M}$. Gaston for his valuable assistance in sampling the ward environment and Mrs $M$. Gosling. Senior Nurse Infection Control.

Casewell M W, Talsania H G, Knight S 1981 Gentamicinresistant Klebsiella aerogenes as a clinically significant source of transferable antibiotic resistance. Journal of Antimicrobial Chemotherapy 8:153-160.

Datta N, Cacey S, Hughes V, Knight S, Richards H, Williams G, Casewell M, Shannon K P 1980 Distribution of genes for trimethoprim and gentamicin resistance in bacteria and their plasmids in a general hospital. Journal of General Microbiology 118:495-508. 
Frost J A, Rowe B, Ward L R, Threlfall, E J 1982 Characterization of resistance plasmids and carried phages in an epidemic clone of multi-resistant Salmonella typhimurium in India. Journal of Hygiene 88:193-204.

Maki D G, Alvardo C J, Hassemer C A, Zilz M A 1982 Relation of the inanimate hospital environment to endemic nosocomial infection. New England Journal of Medicine 307:15621566.

Milch H, Ke N T 1981 Klebsiella and Enterobacter strains derived from hospital infections. 2. Occurrence and characterization of R-plasmids, LAC plasmids and COL plasmids and their clinical epidemiological significance. Acta Microbiologica Academiae Scientiarum Hungaricae 28:171-196.

O'Brien T F, Ross D G, Guzman M A, Medeiros A A, Hedges R W, Botstein D, 1980 Dissemination of an antibiotic resistance plasmid in hospital patient flora. Antimicrobial Agents and Chemotherapy 17:537-543.

Petrocheilou V, Grinsted J, Richmond M H 1976 R-plasmid transfer in vivo in the absence of antibiotic selection pressure. Antimicrobial Agents and Chemotherapy 10:753761.

Rennie R P, Duncan I B R 1977 Emergence of gentamicinresistant Klebsiella in a general hospital. Antimicrobial Agents and Chemotherapy 11:179-184.

Rubens C E,. Farrar W E, McGee Z A, Schaffner W 1981 Evolution of a plasmid mediating resistance to multiple antimicrobial agents during a prolonged epidemic of nosocomial infections. Journal of Infectious Diseases 143:170181 .

Tompkins L S, Plorde J J, Falkow S 1980 Molecular analysis of $\mathrm{R}$-factors from multiresistant nosocomial isolates. Journal of Infectious Diseases 141:625-636.

Wenzel R P, Veazey J M, Townsend T R 1977 Role of the inanimate environment in hospital-acquired infections. Cundy K R, Ball W (eds) In: Infection control in health care facilities: microbiological surveillance. University Park Press, Baltimore, MD, pp 71-143. 